\title{
Psychosis in high-security and general psychiatric services
}

\author{
Report from the UK700 and Special Hospitals' Treatment \\ Resistant Schizophrenia groups
}

E. WALSH, M. LEESE, P. J. TAYLOR, I. JOHNSTON, T. BURNS, F. CREED, A. HIGGITT and R. MURRAY

\section{Background Serious violence is an unusual but significant correlate of psychosis, and leads to the need for specialist secure psychiatric services. Most such service users have previously used general psychiatric services.}

Aims To examine diagnostic and sociodemographic differences between highsecurity psychiatric service users from their peers in community services.

Method Two groups of patients with psychosis were compared: a national sample of high-security hospital residents, and a sample of patients in contact with general psychiatric services.

Results Schizophrenia was the almost invariable diagnosis for all special hospital patients.White patients in the community sample were significantly more likely to have affective components to their illness compared with African-Caribbean patients; unlike those in special hospitals. There was a small excess in the proportion of African-Caribbean patients in the special hospital group, controlling for diagnosis, gender and locality. Men were overrepresented in this group.

Conclusions Among patients with psychosis, having a diagnosis of schizophrenia and being male increase the likelihood of special hospital admission. Suggestions that ethnic minority patients are much more likely to have engaged in serious violence and need high-security placement were not borne out.

Declaration of interest Funding is detailed in the Acknowledgements.
A significant association between psychosis and violence (Swanson et al, 1990; Hodgins, 1992; Hodgins et al, 1996; Tiihonen et al, 1997) has been consistently demonstrated. Research must now elucidate the complex pathways that lead to violence in the context of psychosis. One approach is to compare samples of people with wellestablished psychosis, one of which is made up of people who have been seriously violent and the other of those who have not. Special hospitals provide security and treatment for people with mental disorders who are judged to need such conditions on account of their dangerous, violent or criminal propensities (Taylor et al, 1998). Little is known about the pathways into special (high-security) hospitals, although it has been suggested that certain ethnic minorities may be overrepresented. A recent study found that compared with White men, Black men were nearly six times more likely to be admitted to secure forensic facilities. In contrast, Asian men were only half as likely to be admitted as White men (Coid et al, 2000). A Scottish study (McMiller et al, 2000) compared patients with schizophrenia living in the community with those resident in the state hospital that provides secure psychiatric care for Scotland. Demographic features associated with admission to special hospital included being male, never married, of lower occupational level and having no qualifications. The Scottish patients were White, indigenous people without ethnic minority representation.

Our aim was to explore the diagnostic and socio-demographic factors that distinguish high-security psychotic patients from those in general psychiatric services. We did this by comparing a complete national sample of patients with psychosis resident in high-security hospitals, and a sample of patients with psychosis with wellestablished illnesses and experience of non-secure psychiatric hospital in-patient care.

\section{METHOD}

\section{Sample}

Two samples of patients were recruited who met the same criteria for psychosis and were in the same age range, but differed in that the first were in special (high-security) hospitals while the second were living in the community. The highsecurity hospital sample consisted of all patients 16-65 years of age with a psychotic diagnosis, according to the ICD-10 (World Health Organization, 1992, 1994), resident in English special hospitals (Ashworth, Broadmoor and Rampton) at any time between 1 January 1993 and 30 June 1993. Of the 1740 patients resident at that time, 905 had a diagnosis of psychosis and were included in the study. A large proportion had previously been in contact with psychiatric services: $623(75 \%)$ of those with schizophrenia, for example, had previously been psychiatric hospital in-patients, and a further $178(22 \%)$ had had some contact with psychiatric services.

The community sample participants were recruited between February 1994 and April 1996 from four inner-city sites (three in London, the other in Manchester) as part of a study of intensive case management, the UK700 trial (Burns et al, 1999). The 708 patients used for this comparison were identified by review of in-patient and out-patient registers and fulfilled the following criteria:

(a) aged 16-65 years;

(b) a primary diagnosis of psychosis, defined according to ICD-10;

(c) hospitalised for psychotic symptoms at least twice, with the most recent admission within the preceding 2 years;

(d) no primary diagnosis of substance misuse or organic brain disease.

With regard to the representativeness of the UK700 sample, $13 \%$ of patients approached for interview refused to participate. A further $7 \%$ were not interviewed for a variety of reasons including inability to give informed consent and inability to establish contact. As it was possible to collect only a limited amount of information on all eligible patients at each site, some comparisons of basic demographic factors (age and gender) and clinical characteristics (duration of illness) were made between those who entered the trial and those who did not. The patients who refused to enter were found to be very 
similar to those who did in terms of sociodemographic factors and illness history. A thorough search of case notes was conducted to determine whether any of the community patients had previously been admitted to a special hospital.

\section{Data collection}

Socio-demographic data for both samples consisted of current age, gender, ethnicity, marital status, number of children and educational achievement. Ethnicity was interviewer-assigned as White, AfricanCaribbean and other (including West African). The Mental Needs Index score (MINI; Glover et al, 1998), based on postcode, was also available for the areas in which the patient lived (or had lived, in the case of special hospital patients). This index is designed to predict the number of people likely to receive in-patient care in a defined area, derived from sociodemographic variables (social isolation, poverty, unemployment, permanent sickness, and temporary and insecure housing). It has been found to predict the substantial variation in mental health care as well as the York index (Carr-Hill et al, 1994) and better than Jarman's Underprivileged Area score (Jarman, 1984).

Data regarding the special hospital patients were collected from case records and supplemented from a research database (the Special Hospital Case Register) drawn from official national records, special hospital records, interviews covering social and offending histories, and brief clinical reports including the admission diagnosis from the psychiatrist in charge of each patient. A diagnosis was made in each case by researchers according to ICD-10 guidelines on the basis of best information available. In a small number of cases where no diagnosis could be made on documentary evidence, the individual's consultant psychiatrist was contacted for clarification. Diagnosis was validated in a random number of non-contentious cases and decided in all disputed cases by a panel of experienced senior psychiatrists brought together for the project.

Patients in the UK700 study group were interviewed and detailed socio-demographic information was recorded in a schedule devised for the trial. Case notes were inspected to supplement and verify interview data. The Operational Criteria Checklist for Psychotic Illness (McGuffin et al, 1991) was completed from medical case notes to generate diagnoses according to ICD-10.

\section{Statistical analysis}

An initial inspection of all variables in each sample was performed. A check was made for missing values, and participants with missing values were excluded from the analysis for the relevant variables. The special hospital sample is a national sample for England and Wales, whereas the UK700 sample are from four inner-city areas in two geographic locations. Area of residence, with its socio-economic implications, is likely to be a relevant variable in association with violence, so close matching on this variable is important. We did this in two ways: first by controlling for the MINI score, and then by using a nested subsample in which UK700 and special hospital patients were matched according to the first three digits of the postcode of the patient's address (last known address in the case of special hospital patients).

In the first, unmatched analysis, the association between special hospital admission and all explanatory variables was examined using logistic regression. Odds ratios with $95 \%$ CIs were estimated. A sub-analysis was performed on the diagnostic data to investigate the relationship between diagnosis and ethnic group; the significance of an interaction term between ethnic group and source (special hospital or community) in relation to diagnosis (schizophrenia $v$. affective disorder) was tested.

The second, matched, analysis made use of address postcodes to define locality. Any special hospital patient who did not reside in an electoral ward area covered by the UK700 sample at the time of admission was excluded from the analysis, as was any UK700 patient who lived in an electoral ward in which no special hospital patient resided, since these provided no useful information on relative odds. Conditional logistic regression was used to estimate unadjusted odds ratios for special hospital admission, matching on locality, and also odds ratios adjusted for all other variables.

All analyses were performed using STATA version 5 (STATA, 1995), using the 'logistic' and 'clogit' commands. Likelihood ratio tests were used to assess the significance of variables in the multivariate models.

\section{RESULTS}

Table 1 shows the demographic and diagnostic profile of the study participants by sample group. The index offences of the special hospital patients included 309 (34\%) homicides, 480 (53\%) other violence, $70(8 \%)$ sexual offences and $46(5 \%)$ arson or property damage. Of the UK700 patients, $129(18 \%)$ had a past violent conviction according to Home Office criminal records. Of the special hospital patients, $228(25 \%)$ were recorded as having a coexisting personality disorder. It is likely that substance misuse was underrecorded: $160(22 \%)$ community patients reported taking one or more illegal drugs in the year prior to recruitment. In the special hospital sample, among those with schizophrenia (who formed the majority of the sample), $13 \%$ had a record of comorbid substance misuse. Variables with a large proportion of missing values were 'marital status' and 'number of children' in the special hospital sample (17\% in each case), and the MINI deprivation score in both samples $(18 \%$ and $16 \%$ for the UK700 and the special hospital samples respectively). Five community patients were recorded as having been admitted to a special hospital at some point in their lives, but exclusion of these patients from the analysis made little difference to the results.

It is clear that there are marked differences between the two groups, and because some of these differences may be explicable by socio-economic factors, we proceeded directly to comparisons controlling for the MINI score. The median MINI score of 445 (interquartile range 376-495) for the community sample was significantly higher than that for the special hospital patients (318; interquartile range 230-418, $P<0.001$ ), representing higher levels of socio-economic deprivation in the community sample. This is hardly surprising, as the community sample participants were recruited from inner-city areas, whereas the special hospital group were a national sample. After adjusting for the MINI score, special hospital patients were found to be significantly more likely to be male, single, with lower educational achievements and to have a diagnosis of schizophrenia, than the community-dwelling sample. Male gender and a diagnosis of schizophrenia remained significant in the multivariate model.

Examining diagnosis in relation to the type of sample and ethnic group (Table 2), 
Table I Demographic comparison of study participants from the special hospital compared with the UK700 group

\begin{tabular}{|c|c|c|c|c|}
\hline \multirow[t]{2}{*}{ Factor } & \multirow[t]{2}{*}{ UK700 group $n=708$} & \multirow[t]{2}{*}{ Special hospital group $n=905$} & \multicolumn{2}{|c|}{ Odds ratio $(95 \% \mathrm{Cl})$} \\
\hline & & & Adjusted for MINI only & $\begin{array}{c}\text { Adjusted for MINI and all other } \\
\text { variables }\end{array}$ \\
\hline Age in years: median (range) & $36(22-60)$ & $38(25-57)$ & $\mathrm{I} .0(0.99-1.0 \mathrm{I})^{1}$ & $1.00(0.99-1.02)^{1}$ \\
\hline \multicolumn{5}{|l|}{ Gender: $n(\%)$} \\
\hline Female & $304(42.9)$ & $100(I I . I)$ & I*** & I*** \\
\hline Male & $404(57.1)$ & $805(88.9)$ & $7.16(5.06-10.14)$ & $7.00(4.55-10.76)$ \\
\hline \multicolumn{5}{|l|}{ Ethnicity: $n(\%)^{2}$} \\
\hline White & $367(51.9)$ & $618(68.3)$ & $\mid * * *$ & $\mid * * *$ \\
\hline African-Caribbean & $196(27.7)$ & $177(19.6)$ & $\mathrm{I} .06(0.78-\mathrm{I} .45)$ & $0.86(0.59-1.25)$ \\
\hline Other & $144(20.4)$ & $110(12.1)$ & $0.47(0.33-0.68)$ & $0.23(0.14-0.38)$ \\
\hline \multicolumn{5}{|l|}{ Marital status: $\boldsymbol{n}(\%)^{3}$} \\
\hline Ever married & $244(34.5)$ & $172(22.8)$ & $\mathrm{I} * *$ & I \\
\hline Single & $463(65.5)$ & $583(77.2)$ & $1.51(1.12-2.04)$ & $1.24(0.8 \mathrm{I}-\mathrm{I} .90)$ \\
\hline \multicolumn{5}{|l|}{ Children: $n(\%)^{4}$} \\
\hline No & $400(56.7)$ & $506(67.7)$ & 1 & $\mathrm{I}$ \\
\hline Yes & $305(43.3)$ & $242(32.3)$ & $0.77(0.58-1.02)$ & $\mathrm{I} .08(0.78-\mathrm{I} .49)$ \\
\hline \multicolumn{5}{|l|}{ Qualifications: $n(\%)^{5}$} \\
\hline None & $313(45.0)$ & $54 \mid(64.4)$ & $\mathrm{I} * * *$ & $\mid * * *$ \\
\hline CSE/GCSE/O-level & $224(32.2)$ & $205(24.4)$ & $0.46(0.33-0.63)$ & $0.52(0.35-0.74)$ \\
\hline A-Level/degree & $158(22.7)$ & $93(11.1)$ & $0.23(0.16-0.36)$ & $0.30(0.19-0.48)$ \\
\hline \multicolumn{5}{|l|}{ Diagnosis: $n(\%)^{6}$} \\
\hline Schizophrenia & $388(56)$ & $737(81)$ & $\mid * * *$ & $I^{* *}$ \\
\hline Schizoaffective disorder & $104(15)$ & $52(6)$ & $0.37(0.23-0.59)$ & $0.46(0.26-0.83)$ \\
\hline Affective disorder & $86(13)$ & $28(3)$ & $0.18(0.10-0.32)$ & $0.35(0.19-0.69)$ \\
\hline Other & $113(16)$ & $88(10)$ & $0.43(0.29-0.64)$ & $0.72(0.45-1.16)$ \\
\hline
\end{tabular}

I. Per 10-year increase in age.

2. Data on ethnicity missing for I in the UK700 group.

3. Data on marital status missing for I in the UK700 group and $I 50$ in the special hospital group.

4. Data on children missing for 3 in the UK700 group and 157 in the special hospital group.

5. Data on qualifications missing for 13 in the UK700 group and 66 in the special hospital group.

6. Data on ethnicity missing for 17 in the UK700 group.

Odds ratio, special hospital compared with UK700.

$\mathrm{Cl}$, confidence interval; MINI, Mental Needs Index.

$* * P<0.01, * * * P<0.001$.

Table 2 Diagnosis and ethnic group allocation of the study sample

\begin{tabular}{lccc}
\hline & White $n(\%)$ & African-Caribbean $n(\%)$ & Total $n(\%)^{\prime}$ \\
\hline $\begin{array}{l}\text { Special hospital group } \\
\text { Schizophrenia }\end{array}$ & $500(91.2)$ & $148(88.1)$ & $648(90.5)$ \\
$\quad$ Schizoaffective or affective disorder & $48(8.8)$ & $20(11.9)$ & $68(9.5)$ \\
$\begin{array}{l}\text { Community group } \\
\text { Schizophrenia } \\
\text { Schizoaffective or affective disorder }\end{array}$ & $179(62.2)$ & $130(75.6)$ & $309(67.5)$ \\
\hline
\end{tabular}

I. 'Other' diagnostic and ethnic groups excluded.

it is clear that those in the special hospital sample are more likely to be diagnosed with schizophrenia than members of the community sample. However, the pattern is somewhat different in the two samples. In the special hospital sample the proportion of non-schizophrenia diagnoses is similar (and low) for the White and African-Caribbean groups, whereas in the community sample the proportion of non-schizophrenia diagnoses is higher overall, but differs between ethnic groups. In a logistic regression of diagnostic group as the dependent variable (schizophrenia $v$. schizoaffective or affective disorder), the interaction of ethnic group and sample type was significant at $P=0.003$, confirming this apparently different pattern.

In order to reduce geographic sampling bias (especially in comparing the proportions of different ethnic groups) in the UK700 group, locality-matched subsamples were compared. In this analysis, when special hospital patients who were found not to have lived in any of the same localities as the UK700 patients were excluded, 65 remained. Similarly, after exclusion of UK700 patients who lived in localities where no special hospital patients had resided, 331 remained. Table 3 shows the unadjusted and adjusted odds ratios estimated from a conditional logistic regression 
Table 3 Demographic comparison of a subsample of participants from the special hospital and UK700 groups matched for postcode locality

\begin{tabular}{|c|c|c|c|c|}
\hline \multirow[t]{2}{*}{ Factor } & \multirow[t]{2}{*}{ UK700 group $n=331$} & \multirow[t]{2}{*}{ Special hospital group $n=65$} & \multicolumn{2}{|c|}{ Odds ratio $(95 \% \mathrm{Cl})$} \\
\hline & & & Unadjusted & Adjusted for all other variables \\
\hline Age in years: median (range) & $35(22-6 I)$ & $35(22-55)$ & $0.82(0.63-1.14)^{\prime}$ & $0.8 \mathrm{I}(0.59-\mathrm{I} .2 \mathrm{I})^{\prime}$ \\
\hline \multicolumn{5}{|l|}{ Gender: $n$ (\%) } \\
\hline Female & $138(4 \mid .7)$ & $4(6.2)$ & $\left.\right|^{* * *}$ & $\mathrm{I}$ \\
\hline Male & $193(58.3)$ & $61(93.8)$ & $9.31(3.21-27.0)$ & $6.68(2.04-21.80)^{* * *}$ \\
\hline \multicolumn{5}{|l|}{ Ethnicity: $n(\%)$} \\
\hline White & $165(49.9)$ & $35(53.8)$ & $I^{* *}$ & $I^{*}$ \\
\hline African-Caribbean & $102(30.8)$ & $25(38.5)$ & $1.97(0.98-3.94)$ & I.3I (0.56-3.09) \\
\hline Other & $64(19.3)$ & $5(7.6)$ & $0.45(0.14-\mathrm{I} .40)$ & $0.17(0.03-0.98)$ \\
\hline \multicolumn{5}{|l|}{ Marital status: $n(\%)^{2}$} \\
\hline Single & $218(65.8)$ & 45 (78.9) & I & 1 \\
\hline Ever married & $\mathrm{II} 3(34.2)$ & $12(2 \mid . I)$ & $0.7 \mid(0.33-1.5)$ & $1.59(0.51-3.52)$ \\
\hline \multicolumn{5}{|l|}{ Children: $n(\%)^{3}$} \\
\hline No & $185(56.1)$ & $37(64.9)$ & I & I \\
\hline Yes & $145(43.9)$ & $20(35.1)$ & $0.89(0.46-I .7 I)$ & $\mathrm{I} .34(0.5 \mathrm{I}-3.52)$ \\
\hline \multicolumn{5}{|l|}{ Qualifications: $n(\%)^{4}$} \\
\hline None & $157(48.5)$ & $39(60.2)$ & $\mathbf{I}$ & $\mathrm{I}$ \\
\hline CSE/GCSE/O-level & $102(31.5)$ & $16(24.6)$ & $0.71(0.34-1.47)$ & $0.95(0.4 I-2.23)$ \\
\hline A-Level/degree & $65(20.0)$ & $10(15.2)$ & $0.43(0.16-1.17)$ & $0.85(0.24-3.02)$ \\
\hline \multicolumn{5}{|l|}{ Diagnosis: $n(\%)^{5}$} \\
\hline Schizophrenia & $175(54.1)$ & $53(81.5)$ & I*** & I \\
\hline Schizoaffective disorder & $5 \mathrm{I}(\mathrm{I5.7)}$ & $6(9.2)$ & $0.49(0.18-1.37)$ & $0.53(0.16-1.74)$ \\
\hline Affective disorder & $52(16.1)$ & $2(3.1)$ & $0.08(0.02-0.43)$ & $0.17(0.03-1.03)$ \\
\hline Other & $46(14.2)$ & $4(6.2)$ & $0.17(0.04-0.72)$ & $0.21(0.04-I .1 I)$ \\
\hline
\end{tabular}

I. Per 10 -year increase in age.

2. Data on marital status missing for 8 in the special hospital group.

3. Data on children missing for I in the UK700 group and 8 in the special hospital group.

4. Data on qualifications missing for 7 in the UK700 group.

5. Data on diagnosis missing for 7 in the UK700 group.

$* P<0.05, * * P<0.01$, ***P $<0.001$.

analysis matching for locality. In this smaller matched sample the odds ratios were very similar to those found using the larger sample controlling for MINI score.

The overall significance of the ethnic variable is derived from the 'other' ethnic group. However, this group is too small and heterogenous for meaningful analysis. There is some evidence of a higher (although non-significant) odds ratio for African-Caribbean compared with White ethnicity in the special hospital sample compared with the community sample, although the odds ratio drops from 1.97 to 1.31 after controlling for other sociodemographic factors. The primary reason for the reduction was the inclusion in the model of diagnosis and gender. The overall proportions for the locality-matched subsamples are $38 \%$ for African-Caribbeans in the special hospitals and $3 \%$ in the UK700 sample.

\section{DISCUSSION}

In the first study in England and Wales to compare the socio-demographic and diagnostic differences between psychotic individuals who were committed to a special hospital and those who were not, we found schizophrenia to be the almost invariable diagnosis for all special hospital patients. White patients in the community sample were significantly more likely to have affective components to their illness compared with African-Caribbean patients. There was a small, non-significant increase in the proportion of African-Caribbean patients in special hospitals but this could largely be accounted for by diagnosis and gender. Male overrepresentation in the special hospitals was evident.

\section{Diagnostic differences}

Those admitted to a special hospital were significantly more likely to be diagnosed with schizophrenia than those in the community sample, irrespective of ethnic origin. This supports the widely replicated finding of a significant association between schizophrenia and violence (Eronen et al, 1996; Tiihonen et al, 1997; Brennan et al, 2000), which has been shown to be independent of the risk from associated substance misuse (Brennan et al, 2000). In general, affective disorders have not been found to be associated with an increased risk of homicide (Eronen et al, 1996) or violence more generally (Arseneault et al, 2000), although at least one study has 
found such an association (Cote \& Hodgins, 1992). Our finding supports a relationship between serious violence and schizophrenia but not between serious violence and affective disorder. As a result one may speculate that an affective element in psychotic illness may be protective against serious violence and special hospital admission. This requires research that is beyond the scope of this study.

In the community sample, not only was the proportion of people with schizophrenia lower but there also appeared to be a difference between ethnic groups. African-Caribbean patients were substantially less likely to receive a diagnosis of schizoaffective or affective psychosis than White patients. African-Caribbean people in the UK have higher rates of schizophrenia than their White counterparts (Harrison, 1990; Wessely et al, 1991; van Os et al, 1996), an excess that has been shown to extend to Africans (van Os et al, 1996). The possibility of misdiagnosis must, however, be kept in mind. In a study in south London, AfricanCaribbean patients with a diagnosis of bipolar affective disorder attending a lithium clinic were more likely to have mood-incongruent delusions than their White counterparts, and as such ran the risk of being misdiagnosed as having schizophrenia (Kirov \& Murray, 1999). In another study, African Americans with psychosis were more likely than their White counterparts to be diagnosed as having schizophrenia and less likely to be diagnosed as having psychotic depression (Strakowski et al, 1996). The authors suggested that this may be due to the more frequent occurrence of Schneiderian first rank symptoms in Black patients, leading to overdiagnosis of schizophrenia and underdiagnosis of affective psychosis. A complication of misdiagnosis is inappropriate and/or inadequate treatment. Given symptom links with violence (Taylor, 1985; Link \& Stueve, 1995; Taylor et al, 1998), the deterioration in mental health that may accompany such treatment may increase the propensity to violence.

\section{Gender differences}

Our most robust finding, that there are proportionately more men in special hospitals, is hardly surprising, since $90 \%$ of reported violence is perpetrated by men (Monahan, 1993). Because so much research on violence is done in the criminal justice system, data on violence in women with mental disorder are sparse. There have been hints that women with mental disorder equal or exceed their male peers in frequency rather than seriousness of offence. One study showed that a higher proportion of women than men reported at least one violent incident in the community after discharge from hospital (Steadman et al, 1993). Another study showed that during hospitalisation, although men engaged in more fear-inducing behaviour, women engaged in proportionately more physical attacks (Binder \& McNeil, 1990). As such it may be that the crimes committed by women with mental illness are not of a severity to warrant special hospital admission. In fact, in the special hospital sample, the largest single group of women as defined by their index offence had been convicted of criminal damage by fire rather than of serious interpersonal violence (Taylor et al, 1998). Another contributing factor to the low prevalence of women in special hospitals may be that general psychiatric services are more tolerant of an emergent threat from women, enabling a continuity of services that may be vital given symptom links with violence (Taylor, 1985; Link \& Stueve, 1995; Taylor et al, 1998).

\section{Ethnic differences}

A small, non-significant excess was found in the proportion of African-Caribbean patients in special hospitals compared with the community sample, after controlling for locality. African-Caribbean patients are overrepresented in forensic facilities (Jones \& Berry, 1986; Cope \& Ndegwa, 1990; Maden et al, 1999; Coid et al, 2000). These concepts of overrepresentation have frequently (although not exclusively) arisen in relation to comparisons with the general population. The problem with such comparisons is that people of AfricanCaribbean extraction tend also to be overrepresented in in-patient facilities (Wessely et al, 1991; van Os et al, 1996), not just in forensic ones.

It is not known whether a difference exists in the proportion of AfricanCaribbean patients in ordinary psychiatric services and forensic services - that is, do more of this ethnic group end up in secure forensic treatment? This is the question we address here. Our results indicate that, comparing patients living in similar localities, there were proportionately more
African-Caribbean than White people in special hospitals although this difference was at a borderline level of significance, and could be explained partly by other factors such as diagnosis and gender. A recent study showed that among the index offences of individuals admitted to secure forensic services (medium and high security), no difference in the more serious violent offences (homicide, attempted murder, grievous bodily harm) was found between Black (African-Caribbean and Black other) and White individuals. Black patients were, however, more likely to be admitted following minor crimes of violence (assault occasioning actual bodily harm) (Coid et al, 2000). It is thus possible that African-Caribbean patients may be overrepresented in medium-security but not in high-security settings, because when it comes to the more serious forms of violence little difference exists in the ethnicity of offenders.

\section{Methodological considerations}

Choosing a comparison group for special hospital patients is difficult because of their unique status. Prison populations are similarly confined but are not (exclusively) psychiatric patients. Other psychiatric populations such as the UK700 are not confined and the availability of data for such populations depends on agreement to take part in the study. The use of case register data for the special hospital group means that few individuals are missed (even though individual data items may not be present), whereas the opposite is true of the UK700 group, here individuals may have been missed but data tend to be present for those who have been interviewed. An important further limitation lies in the small number of strictly comparable variables available for study in both samples. Although the close locality-matching was aimed at reducing bias in the comparison of the groups, it reduced the sample sizes considerably, affecting the power for the comparisons and generalisability to the whole population. The aim of our study was to simply compare the two psychotic populations on socio-demographic and diagnostic differences according to treatment location. It can be argued that conclusions regarding violence are limited because not everyone in the special hospital group had committed or been convicted of a violent offence. Coexistent personality disorder and substance misuse are two important variables to 
consider when examining differences between violent and non-violent psychotic populations. We were not, however, comparing violent and non-violent groups per $s e$, considering $18 \%$ of the UK700 community sample had a previous violent criminal conviction and a proportion of those in special hospital were there following non-violent crime. Our aim simply was to consider socio-demographic and diagnostic differences according to treatment location. Despite the outlined limitations, which derive from the need to make secondary analyses of existing data-sets, we believe it is important to attempt to make direct comparisons of special hospital patients with another psychiatric sample in England and Wales.

\section{ACKNOWLEDGEMENTS}

Dr Elizabeth Walsh was funded by a Wellcome Training Fellowship. The UK700 trial was funded by grants from the UK Department of Health and the NHS Research and Development programme. The grant-giving body for the Treatment Resistant Schizophrenia Study was formerly the Special Hospitals Service Authority and is currently the National Programme on Forensic Mental Health Research and Development.

The views expressed in this paper do not necessarily reflect those of the Department of Health.

The UK700 Group is a collaborative study team in volving four clinical centres. Manchester: Tom Butler, Francis Creed, Janelle Fraser, Peter Huxley, Nicholas Tarrier, Theresa Tattan.

King's College/Maudsley Hospital, London: Tom Fahy, Karyna Gilvarry, Kwame McKenzie, Robin Murray, Jim van Os, Elizabeth Walsh.

St Mary's/St Charles' Hospitals, London: John Green, Anna Higgitt, Elizabeth van Horn, Donal Leddy, Catherine Manley, Patricia Thornton, Peter Tyrer

St George's Hospital, London: Rob Bale, Tom Burns, Matthew Fiander, Kate Harvey, Andy Kent, Chiara Samele.

York University (Health Economics): Sarah Byford, David Torgerson, Ken Wright.

London School of Hygiene and Tropical Medicine Statistical Centre: SimonThompson, lan White.

\section{The Special Hospitals' Treatment Resistant Schizophrenia Research Group}

Pamela J. Taylor, Institute of Psychiatry; Martin Butwell, Broadmoor Hospital; Colin Gray, Carstairs Hospital; Rachel Daly, Rampton Hospital; Brian Delal, Rampton Hospital; Dana Ferraro, Institute of Psychiatry; Robert Gibb, Ashworth Hospital; Tracy Heads, Broadmoor Hospital; Bernard Huckstep, Rampton Hospital; Emmet Larkin, Rampton Hospital; Morven Leese, Institute of Psychiatry; Girish

\section{CLINICAL IMPLICATIONS}

- A locality-matched analysis revealed a small, non-significant excess in the proportion of African-Caribbean patients compared with White patients in the special hospital sample.

General psychiatric services may be more tolerant of the risk of violence from women than from men.

- An affective component to psychotic illness may be protective against violent behaviour.

\section{LIMITATIONS}

Close locality-matching aimed at reducing selection bias reduced the sample size, affecting the power for comparisons.

- A considerable number of postcodes were missing from both samples.

- Selection bias may have played a role in the findings, as the control group were from inner-city areas rather than being a representative national sample.

ELIZABETH WALSH, MRCPsych, MORVEN LEESE, PhD, PAMELA TAYLOR, FRCPsych, INGRID JOHNSTON, BSc, Institute of Psychiatry, London; TOM BURNS, MD, St George's Hospital Medical School, London; FRANCIS CREED, MD, School of Psychiatry and Behavioural Sciences, University of Manchester; ANNA HIGGIT, MRCPsych, St Charles' Hospital, London; ROBIN MURRAY, DSc, Institute of Psychiatry, London, UK

Correspondence: Dr Elizabeth Walsh, Section of Forensic Mental Health, Division of Psychological Medicine, Institute of Psychiatry, De Crespigny Park, Denmark Hill, London SE5 8AF, UK

(First received 5 July 200I, accepted 5 October 200I)

Shetty, Ashworth Hospital; Mark Swinton, Ashworth Hospital; David Tidmarsh, Broadmoor Hospital; Deborah Williams, Rampton Hospital.

\section{REFERENCES}

Arseneault, L., Moffitt, T. E., Caspi, A., et al (2000) Mental disorders and violence in a total birth cohort: results from the Dunedin study. Archives of General Psychiatry, 57, 979-986.

Binder, R. L. \& McNeil, D. E. (1990) The relationship of gender to violent behaviour in acutely disturbed psychiatric patients. Journal of Clinical Psychiatry, 5I $\| 10-114$.

Brennan, P., Mednick, S. A. \& Hodgins, S. (2000) Major mental disorders and criminal violence in a Danish birth cohort. Archives of General Psychiatry, 57, 494-500.

Burns, T., Creed, F., Fahy, T., et al for the UK700 Group (1999) Intensive versus standard case management for severe psychotic illness: a randomised trial. Lancet, 353, 2185-2189.

Carr-Hill, R. A., Hardman, G., Martin, S., et al (1994) A Formula for Distributing NHS Revenues Based on Small Area use of Hospital Beds. York: Centre for Health Economics, University of York.
Coid, J.W., Nadji, K., Gault, S., et al (2000) Ethnic differences in admissions to secure forensic psychiatry services. British Journal of Psychiatry, 177, 24I-247.

Cope, R. \& Ndegwa, D. (1990) Ethnic differences in admissions to a regional secure unit. Journal of Forensic Psychiatry, I, 365-378.

Cote, G. \& Hodgins, S. (1992) The prevalence of major mental disorders among homicide offenders. International Journal of Law and Psychiatry, 15, 89-99.

Eronen, M., Hakola, P. \& Tiihonen, J. (1996) Menta disorders and homicidal behaviour in Finland. Archives of General Psychiatry, 53, 497-50I.

Glover, G. R., Robin, E., Emami, J., et al (1998) A needs index for mental health care. Social Psychiatry and Psychiatric Epidemiology, 33, 89-96.

Harrison, G. (1990) Searching for the causes of schizophrenia: the role of migrant studies. Schizophrenia Bulletin, 16, 663-67I.

Hodgins, S. (1992) Mental disorder, intellectual deficiency and crime. Archives of General Psychiatry, 49 476-483.

, Mednick, S. A., Brennan, P. A., et al (1996) Mental disorder and crime: evidence from a Danish birth cohort. Archives of General Psychiatry, 54, 489-496.

Jarman, B. (1984) Underprivileged areas: validation and distribution scores. BMJ, 298, 1587-1592. 
Jones, G. \& Berry, M. (1986) Regional secure units; the emerging picture. In Current Issues in Clinical Psychology IV (ed. G. Edwards), pp. 24-42. London: Plenum.

Kirov, G. \& Murray, R. M. (1999) Ethnic differences in the presentation of bipolar affective disorder. European Psychiatry, 14, 199-204.

Link, B. G. \& Stueve, A. (1995) Evidence bearing on mental illness as a possible cause of violent behaviour. Epidemiologic Reviews, I7, 172-181.

Maden, A., Friendship, C., McClintock, T., et al (1999) Outcome of admission to a medium secure psychiatric unit. 2. Role of ethnic origin. British Journal of Psychiatry, 175, 317-32I.

McGuffin, P., Farmer, A. E. \& Harvey, I. (1991) A polydiagnostic application of operational criteria in psychotic illness. Archives of General Psychiatry, 48, 50-55

McMiller, P., Johnstone, E. C., Lang, F. H., et al (2000) Differences between patients with schizophrenia within and without a high security psychiatric hospital. Acta Psychiatrica Scandinavica, 102, 12-18.
Monahan, J. (1993) Causes of violence. In Drugs and Violence in America (ed. USS Commission). Washington, DC: US Government Printing Office.

STATA (1995) STATA Statistical Software release 5.0. College Station, TX: STATA Corporation.

Strakowski, S. M., Flaum, M., Amador, X., et al (1996) Racial differences in the diagnosis of psychosis Schizophrenia Research, 2I, I17-124.

Steadman, H. J., Monahan, J., Robbins, P. C., et a (1993) From dangerousness to risk assessment: implications for appropriate research strategies. In Mental Disorder and Crime (ed. S. Hodgins), pp. 39-61. London: Sage.

Swanson, J.W., Holzer, C. E., Ganju, V. K., et al (1990)

Violence and psychiatric disorder in the community: evidence from the epidemiologic catchment area surveys. Hospital and Community Psychiatry, 4I, 761-770.

Taylor, P. J. (1985) Motives for offending among violent and psychotic men. British Journal of Psychiatry, 147 $491-498$
— , Leese, M., Williams, D., et al (1998) Menta disorder and violence. A special (high security) hospital study. British Journal of Psychiatry, 172, 218-226.

Tiihonen, J., Isohanni, M., Räsänen, P., et al (1997) Specific major mental disorders and criminality: a 26 year prospective study of the 1966 Finland birth cohort. American Journal of Psychiatry, 154, 840-845.

Van Os, J., Castle, D. J., Takei, N., et al (1996)

Psychotic illness in ethnic minorities: clarification from the 199I census. Psychological Medicine, 26, 203-208.

Wessely, S., Castle, D., Der, G., et al (1991)

Schizophrenia and Afro-Caribbeans. A case contro study. British Journal of Psychiatry, 159, 795-801.

World Health Organization (1992) The ICD-IO Classification of Mental and Behavioural Disorders. Geneva: WHO.

- (1994) The ICD-10 Classification of Mental and Behavioural Disorders: Diagnostic Criteria for Research. Geneva: WHO. 